\title{
Potensi Arang Aktif dari Limbah Sabut Pinang (Areca catechu L) Provinsi Jambi sebagai Biosorben
}

Wiji Utami ${ }^{a}$, Devie Novallyan ${ }^{b}$

${ }^{a}$ Kimia, Universitas Islam negeri Sulthan Thaha Saifuddin Jambi, Jl.Jambi Ma. Bulian, KM. 16 3636, Muara Jambi, email:wijiutami@uinjambi.ac.id ${ }^{b}$ Tadris Biologi, Universitas Islam negeri Sulthan Thaha Saifuddin Jambi, Jl.Jambi Ma. Bulian, KM. 16 3636, Muara Jambi

\section{Article Info}

\section{Article history:}

Received 20 Mei 2019

Received in revised form 27 Mei 2019

Accepted 25 Juni 2019

\section{DOI:}

http://doi.org/10.32938/slk.v2il.628

Keywords:

arang aktif

biosorben

limbah sabut pinang

\section{Pendahuluan}

Air merupakan komponen abiotik yang sangat dibutuhkan oleh makhluk hidup untuk melangsungkan hidupnya. Saat ini kebutuhan akan air bersih terus meningkat seiring bertambahnya jumlah penduduk di dunia. Beberapa organisas dunia melaporkan bahwa $70 \%$ penggunaan air bersih global untuk irigasi dan pembuatan makanan, dan penggunaan air itu diperkirakan akan meningkat $19 \%$ mengikuti pertumbuhan populasi secara global 40 tahun yg akan datang (Wong dkk.,2018). Namun, kegiatan urbanisasi dan industri banyak menyebabkan pencemaran perairan (Gupta dkk.,2016; Ammari 2014; Lalhmunsiama dkk. 2013). Pencemar yang sering dijumpai yaitu logam berat $\left(\mathrm{Zn}^{2+}, \mathrm{Cu}^{2+}, \mathrm{Ni}^{2+}, \mathrm{Cd}^{2+}\right.$ $\mathrm{Pb}^{2+}, \mathrm{Cr}^{6+}, \mathrm{Hg}^{2+}$ ) (Ahmad and Haseeb 2017; Gupta dkk., 2016), polutan organik, zat warna, dan pestisida (Singh dkk., 2018). Keberadaan polutan tersebut sangat berbahaya jika tersuspensi di dalam air meskipun dalam konsentrasi yang rendah sekalipun. Oleh karena itu, kontaminasi air oleh polutan merupakan masalah lingkungan dan kesehatan dunia (Ammari, 2014; Binoj dkk., 2016), sehingga membutuhkan sebuah teknik pengolahan air menjadi air yang dapat digunakan untuk memenuhi kebutuhan manusia.

Air yang tercemar berbagai macam polutan termasuk logam berat akan menyebabkan berbagai gangguan kepada makhluk hidup yang memanfaatkannya. Beberapa Gangguan tersebut misalnya parkinson, pernafasan kronis, karsinogenik (Rani dkk., 2018), dan brain disorder (Ebrahimzadeh dkk. 2015; Siddiqui and Ahmad 2017). Terdapat begitu banyak metode dalam proses pengolahan air tercemar yaitu presipitasi, ekstraksi pelarut, reverse osmosis (RO), pertukaran kation, oksidasi reduksi kimia (Dickhout dkk., 2017), koagulan, evaporasi, pemisahan membran (Dickhout dkk., 2017; Lalhmunsiama dkk., 2013). Metode konvensional tersebut memerlukan biaya yang sangat tingg sehingga para ilmuan berusaha untuk mencari metode alternatif lainnya. Metode alternatif tersebut adalah metode adsorpsi yang memiliki keuntungan yaitu tingginya selektifitas, lebih efisiensi, mudah dioperasikan, ekonomis untuk skala besar, dan ramah lingkungan (Chakravarty dkk., 2012; Ammari 2014; Benaïssa and Elouchdi, 2007; Liu dkk., 2014; Shakoor dkk., 2016; Puranik and Paknika 1997), regenerasi, dan minimalisir lumpur (Kim dkk., 2015).

Saat ini material biosorben banyak diperoleh dari bahan produk samping bidang pertanian dan limbah bidang industri. Hal ini memberikan dampak yang baik yaitu dengan pemanfaatan limbah maka dapat mengurangi jumlah limbah secara perlahan. Biosorben yang baik dapat didesain dari bahan baku limbah pertanian, alga (Dickhout dkk., 2017), jamur (Burakov dkk., 2018), bakteri, limbah rumah tangga, industri, dan biomaterial lainnya (Kim dkk., 2015).

Tanaman pinang (Areca catechu L.) mengandung berbagai zat kimia dengan berbagai manfaat untuk bahan baku industri farmasi. Tanaman pinang tersebar di Cina, Taiwan, Florida bagian selatan dan daerah tropis seperti Indonesia (Zheng dkk., 2008). Provinsi Jambi merupakan salah satu provinsi penghasi tanaman pinang terbesar di Pulau Sumatera. Sisa pengolahan pinang menghasilkan limbah padat (Perdagangan, 2017). Sabut buah pinang mengandung beberapa komposisi senyawa kimia yaitu selulosa $(63,20 \%)$, hemiselulosa (32,98\%), lignin (7,20\%), dan lemak (0,64\%) (Muslim dkk., 2015) Senyawa kimia tersebut merupakan sumber karbon dalam pembuatan arang aktif atau adsorben (Li dkk., 2010). Kajian terdahulu telah menunjukkan bahwa tanaman pinang efektif sebagai adsorben dalam menjerap logam berat, sepert besi (Nabanita and Sarma 2012), kation $\mathrm{Cd}^{2+}$ dan $\mathrm{Cu}^{2+}$ (Zheng dkk., 2008), kation $\mathrm{Cu}^{2+}$ (Muslim dkk., 2015), dan kation $\mathrm{Pb}^{2+}$ (Li dkk., 2010). Oleh karena itu, penelitian ini bertujuan untuk mensintesis biosorben dari limbah sabut pinang (Areca catechu L). Tujuan spesifik penelitian ini adalah untuk mengetahui kada air, kadar abu, gugus fungsional, dan luas permukaan dari material biosorben yang telah disintesis sehingga berpotensi digunakan sebagai biosorben.

\section{Metod}

\subsection{Preparasi Biosorben}

Limbah sabut pinang (Areca catechu L) telah diperoleh dari Kabupaten Tanjung Jabung Timur sebagai residu padat dari pengolahan biji pinang. Sabut kulit pinang dicuci menggunakan air bersih untuk menghilangkan pengotor sebelum dilakukan pembuatan biosorben, kemudian dikeringkan di bawah sinar matahari selama 5 hari. Limbah sabut pinang selanjutnya dipotong-potong dengan ukuran 1 x $1 \mathrm{~cm}$ untuk mempercepat reaksi pembuatan biosorben. Limbah sabut pinang yang bersih kemudian dikeringkan di dalam oven pada 110 $\mathrm{C}$ selama 2 jam untuk menghilangkan kandungan $\mathrm{H}_{2} \mathrm{O}$ yang tersisa (Palanichamy and Ariharaputhiran 2013). Perlakuan yang dilakukan pada sampel yaitu karbonisasi dan tanpa karbonisasi. Sampel yang diproses tanpa karbonisasi yaitu langsung digerus dan diayak menggunakan ayakan 100 mesh

Proses karbonisasi dilakukan di Laboratorium Peternakan Universitas Jambi pada suhu 300 dan $400{ }^{\circ} \mathrm{C}$ selama 1 jam menggunakan instrumen Furnace. Setelah proses karbonisasi selesai, sampel limbah diayak menggunakan ayakan 100 mesh sehingga akan menghasilkan bubuk arang aktif dengan ukuran $149 \mu \mathrm{m}$. Sampel tersebut disimpan di dalam desikator (Zhang and Chen, 2018).

\subsection{Karakterisasi Biosorben}

Bubuk biosorben dikarakterisasi untuk mengetahui performa dari material berpori tersebut. Karakterisasi tersebut yaitu uji kadar air, kadar abu dan gugus fungsional (Fourier Transform Infrared) di Laboratorium Sains Materia Universitas Riau, dan luas permukaan (Breneur-Emmet-Teller) di Laboratorium Teknik Kimia Institut Teknologi Bandung menggunakan instrumen Quantachrome Instrument (C1994-2010 version 11.0. (Muslim dkk., 2015; Tong dkk., 2011)

\section{Hasil dan Pembahasan}

Pengukuran kadar abu dilakukan untuk mengetahui banyaknya mineral atau logam yang terukur dalam bentuk oksida logam pada material biosorben yang terdapat pada Tabel 1. Selain itu pengukuran kadar abu bertujuan untuk mengetahui kadar senyawa anorganik. Proses penentuan kadar abu dilakukan menggunakan metode gravimetri. Berdasarkan Tabel 1 dapat dilihat bahwa kadar abu material $400^{\circ} \mathrm{C}$ memiliki kandungan terendah dibandingkan materia biosorben lainnya yaitu $10,952 \%$. Hasil pada penelitian ini masih memperlihatkan hasil di atas batas maksimal dari SNI No.06-3730-1995 yaitu 10\%. Jika kadar abu bekisar antara 2-10 \% maka performa biosorben tersebu sangat baik. Karena, dapat memblokir grup senyawa kimia sensitif, sehingga dapat meningkatkan kestabilan termal. Hal ini disebabkan banyaknya kada mineral yang terdapat pada material biosorben. Kadar abu dalam penelitian ini lebih besar dibandingkan penelitian sebelumnya yaitu 2,75\% (SenthilKumar dkk., 2011) dan 5,08 \% (Binoj dkk., 2016).

Tabel 1. Kadar abu biosorben dari limbah sabut pinang

\begin{tabular}{ccc}
\hline Kondisi sampel $\left({ }^{\circ} \mathrm{C}\right.$, Jam $)$ & Kadar abu $(\%)$ & Kadar air $(\%)$ \\
\hline 400,1 & 10,95 & 2 \\
\hline 300,1 & 45,72 & 2 \\
\hline Tanpa karbonisasi & 93,60 & 22 \\
\hline
\end{tabular}

Berdasarkan Tabel 1 dapat dilihat bahwa kadar air yang terdapat pada material biosorben karbonisasi 300 dan $400^{\circ} \mathrm{C}$ memiliki hasil yang sama yaitu 2 $\%$, sedangkan untuk biosorben yang tidak mengalami proses karbonisas memiliki kandungan air tertinggi yaitu 22\%. Kadar air material biosorben sampel karbonisasi 300 dan $400^{\circ}$ C. telah sesuai dengan SNI No. 06-3730-1995 tentang pesyaratan arang aktif yaitu maksimal $15 \%$. Kadar air pada material biosorben tanpa karbonisasi memiliki kadar tertinggi dibandingkan dengan material biosorben lainnya. Semakin rendah kadar air di bawah kadar maksimal yang ditetapkan oleh SNI maka material biosorben tersebut akan memiliki performa yang baik dalam proses adsorpsi dalam fasa larutan. Kadar air pada material yang diproses melalui karbonisasi disebabkan panas yang ada dapat menyebabkan lepasnya molekul air $\left(\mathrm{H}_{2} \mathrm{O}\right)$ dari pori dan permukaan material biosorben tersebut. Sedangkan untuk material tanpa karbonisasi hanya dipanaskan pada suhu 110 $\mathrm{C}$, pada kondisi ini air yang terlepas hanya air yang terdapat pada permukaan material saja. Air yang terdapat pada pori-pori material masih cukup tinggi sehingga hal ini dapat mengurangi performa adsorptivitas material tersebut 
Analisis menggunakan instrumen FTIR dilakukan dengan tujuan untuk mengetahui perbedaan gugus fungsional yang terdapat pada permukaan material biosorbent akibat treatmen yang berbeda terdapat pada Tabel 2. Dengan mengetahui gugus fungsional yang terdapat pada permukaan material maka karakter interaksi antara biosorben dengan adsorbat dapat diketahui (Ahsan dkk., 2018). Berdasarkan Tabel 3 dapat dilihat bahwa terjadi pergeseran puncak yang terjadi secara signifikan. Dimana biosorben tanpa karbonisasi tidak menunjukkan keberadaan puncak yang dominan (dapat dilihat pada Gambar 1). Akan tetapi setelah diberi perlakuan karbonisasi pada suhu 300 dan $400^{\circ} \mathrm{C}$, maka terjadi kemunculan puncak-puncak yang mengindikasi adanya gugus tertentu.

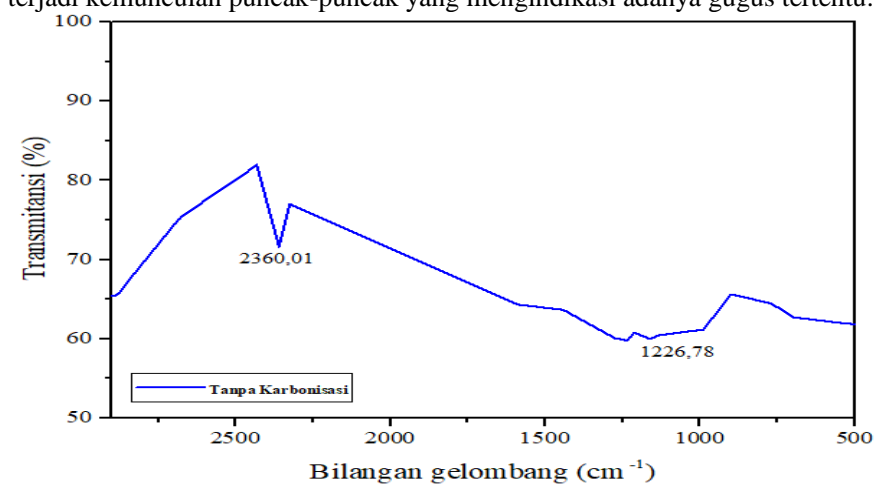

Gambar 1. Spektrum FTIR biosorben dari limbah sabut pinang (Areca catechu L.) tanpa proses karbonisasi.

Berdasarkan Gambar 1 dapat dilihat bahwa, pada biosorben tanpa karbonisasi muncul puncak dominan pada bilangan gelombang $1226,78 \mathrm{~cm}^{-1}$ hal ini sesuai dengan penelitian terdahulu yaitu -C-O stretching $\left(1241 \mathrm{~cm}^{-1}\right)$ (Chakravarty dkk., 2010). Selain itu terjadi pergeseran puncak dari ke 2212,45 $\mathrm{cm}^{-1}\left(300^{\circ} \mathrm{C}\right) \mathrm{ke} 2360,01 \mathrm{~cm}^{-1}\left(400^{\circ} \mathrm{C}\right)$ pada Gambar 2, hal ini menandakan adanya gugus fungsi - $\mathrm{CH}$ (Ahmad and Haseeb, 2017). Pada biosorben 300 dan $400^{\circ} \mathrm{C}$ terdapat puncak sekitar daerah $3160,50 \mathrm{~cm}^{-1}$ dan $3154,71 \mathrm{~cm}^{-1}$ pada puncak tersebut mengindikasi adanya gugus fungsi $-\mathrm{OH}$ (hidroksil) dari alkohol dan fenol yang terdapat pada permukaan material biosorben. Hal ini menyerupai dengan hasil penelitian sebelumnya yaitu pada area puncak $3200-3650 \mathrm{~cm}^{-1}$ (Muslim dkk., 2015).

\begin{tabular}{cccc}
\multicolumn{2}{c}{ Tabel 2. Puncak FTIR biosorben dari limbah sabut pinang } \\
\hline $\begin{array}{c}300^{\circ} \mathrm{C} \\
\left(\mathrm{cm}^{-1}\right)\end{array}$ & $\begin{array}{c}400^{\circ} \mathrm{C} \\
\left(\mathrm{cm}^{-1}\right)\end{array}$ & $\begin{array}{c}\text { Tanpa } \\
\text { karbonisasi } \\
\left(\mathrm{cm}^{-1}\right)\end{array}$ & Keterangan \\
\hline 796,64 & 800,48 & & $\mathrm{C}-\mathrm{H}$ cincin aromatik \\
\hline 1115,87 & 1079,04 & 1226,78 & $\begin{array}{l}\mathrm{C}-\mathrm{O} \text { Alkohol, eter, asam, } \\
\text { karboksilat, ester }\end{array}$ \\
\hline 1530,58 & 1502,61 & & \multicolumn{1}{c}{$\mathrm{NO}_{2}$} \\
\hline 2212,45 & 2360,01 & 2360,01 & $\mathrm{C}=\mathrm{N} \mathrm{Nitril}$ \\
\hline 2660,01 & & & $\begin{array}{l}\text { O-H ikatan hidrogen } \\
\text { karboksilat }\end{array}$ \\
\hline 3160,50 & 3154,71 & & \multicolumn{1}{c}{$\mathrm{O}-\mathrm{H}$} \\
\hline 3659,12 & & $\begin{array}{l}\text { O-H Fenol, monomer } \\
\text { alkohol, alkohol ikatan } \\
\text { hidrogen, fenol }\end{array}$ \\
\hline
\end{tabular}

Serapan muncul $3659,12 \mathrm{~cm}^{-1}$ untuk sampel $300^{\circ} \mathrm{C}$ yang menandakan adanya gugus fungsional - $\mathrm{OH}$ bebas termasuk ikatan hidrogen dari alkohol, fenol dan asam karboksilat (Palanichamy and Ariharaputhiran 2013; Babbington 2007). Puncak 796,64 dan $800,48 \mathrm{~cm}^{-1}$ menandakan adanya gugus fungsi $-\mathrm{CH}-$ dari cincin aromatis, hasil ini mendekati hasil yang diperoleh dari penelitian sebelumnya yaitu 968 dan $623 \mathrm{~cm}^{-1}$ (Fadhil dkk., 2017). Proses karbonisasi yang dilakukan pada suhu 300 dan $400^{\circ} \mathrm{C}$ memberikan pengaruh terhadap pergeseran puncak material biosorben.

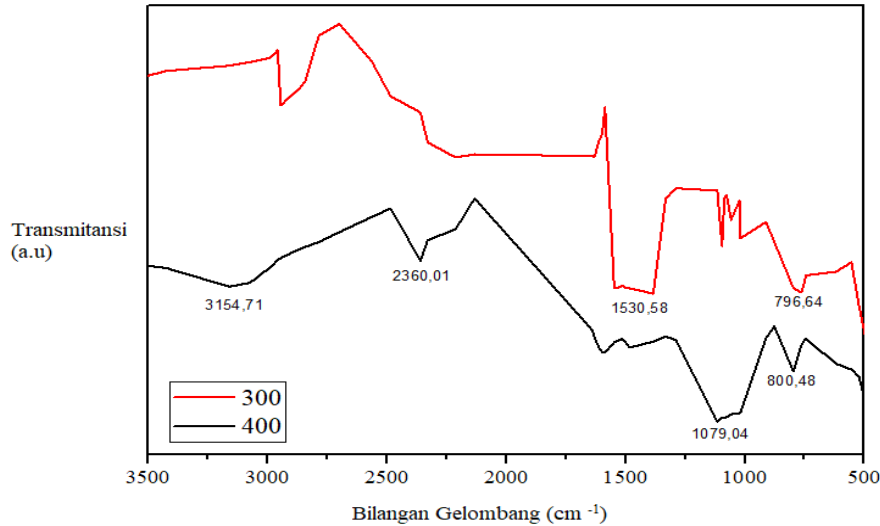

Gambar 2. Spektrum FTIR biosorben dari limbah sabut pinang (Areca catechu L.) dari proses karbonisasi 300 dan $400^{\circ} \mathrm{C}$.
Pengaruh pemanasan terhadap aktivasi permukaan biosorben dapa diketahui dengan melakukan pengukuran luas permukaan pada sampel karbonisasi 300 dan $400^{\circ} \mathrm{C}$. Karakter luas permukaan pada material biosorben berkaitan dengan daya serat terhadap asdorbat, yaitu semakin luas permukaan maka kemampuan adsorpsi semakin meningkat. Data luas permukaan biosorben dapat dilihat pada Tabel 3. Penentuan luas permukaan pada penelitian ini dilakukan menggunakan metode Breneur-Emmet-Teller (BET) dengan hasil tertinggi pada sampel karbonisasi $300^{\circ} \mathrm{C}$.

\begin{tabular}{cc}
\multicolumn{2}{c}{ Tabel 3. Karakterisasi luas permukaan biosorben } \\
\hline Kondisi $\left.\mathbf{~}^{\circ} \mathbf{C}, \mathbf{J a m}\right)$ & Luas permukaan $\left(\mathbf{m}^{\mathbf{2}} \mathbf{g}^{\mathbf{- 1}}\right)$ \\
\hline 300,1 & 25,77 \\
\hline 400,1 & 9,44 \\
\hline
\end{tabular}

Berdasarkan Tabel 4 dapat dilihat bahwa karbonisasi pada suhu $300^{\circ} \mathrm{C}$ memiliki luas permukaan tertinggi, hal ini disebabkan karena proses pemanasan pada suhu tinggi. Proses karbonisasi menyebabkan molekul air yang terdapat pada permukaan dan pori-pori material biosorben menghilang. Hilangnya molekul air menyebabkan pori-pori karbon semakin besar karena molekul air yang terikat ini menutupi pori-pori karbon. Semakin besar pori-pori maka luas permukaan akan semakin bertambah. Luas permukaan akan mempengaruhi kinerja material itu sendiri, bersama porositas pada permukaan material sebagai tempat terjadinya reaksi molekul (adsorbat) dengan gugus fungsi spesifik (Wong dkk., 2018). Hasil analisis luas permukaan pada penelitian ini mendapat hasi yang lebih tinggi dibanding penelitian sebelumnya yaitu $0,97 \mathrm{~m}^{2} \mathrm{~g}^{-1}$ yang terbuat dari gambir (Tong dkk., 2011).

\section{Simpulan}

Penelitian ini memperlihatkan bahwa proses karbonisasi (aktivasi fisika) dapat meningkatkan karakteristik biosorben. Berdasarkan hasil penelitian di atas dapat disimpulkan bahwa kondisi karbonisasi $300^{\circ} \mathrm{C}$ selama 1 jam memberikan luas permukaan yang paling tinggi dengan kadar air sebanyak $2 \%$. Akan tetapi, kadar abu yang dimiliki oleh biosorben 300 lebih tinggi dibanding biosorben 400 C yaitu 45,72 \%. Hal ini menunjukkan bahwa limbah sabut pinang dari Provinsi Jambi berpotensi sebagai bahan pembuatan biosorben. Namun, perlu dilakukan penelitian tingkat lanjut dengan variabel penelitian yang lebih banyak untuk memperoleh kondisi optimum, sehingga akan memperoleh hasil maksimal.

\section{Pustaka}

Ahmad, Rais, and Shazia Haseeb. 2017. "Adsorption of $\mathrm{Pb}(\mathrm{II})$ on Mentha Piperita Carbon (MTC) in Single and Quaternary Systems.” Arabian Journal of Chemistry 10: S412-21. https://doi.org/10.1016/j.arabjc.2012.09.013.

Ahsan, Md Ariful, Vahid Jabbari, Md Tariqul Islam, Hoejin Kim, Jose Angel Hernandez-Viezcas, Yirong Lin, Carlos A. Díaz-Moreno, Jorge Lopez, Jorge Gardea-Torresdey, and Juan C. Noveron. 2018. "Green Synthesis of a Highly Efficient Biosorbent for Organic, Pharmaceutical, and Heavy Metal Pollutants Removal: Engineering Surface Chemistry of Polymeric Biomass of Spent Coffee Waste." Journal of Water Process Engineering 25 (August) 309-19. https://doi.org/10.1016/j.jwpe.2018.08.005.

Ammari, Tarek G. 2014. "Utilization of a Natural Ecosystem Bio-Waste; Leaves of Arundo Donax Reed, as a Raw Material of Low-Cost Eco-Biosorbent for Cadmium Removal from Aqueous Phase." Ecological Engineering 71: 466 73. https://doi.org/10.1016/j.ecoleng.2014.07.067.

Babbington, Gabrielle. 2007. Infant Antibiotics May up Asthma Risk. Australian Doctor. Elsevier Ltd. https://doi.org/10.1016/j.jclepro.2018.06.261.

Benaïssa, H., and M. A. Elouchdi. 2007. "Removal of Copper Ions from Aqueous Solutions by Dried Sunflower Leaves." Chemical Engineering and Processing: $\quad$ Process Intensification 46 (7): 614-22. https://doi.org/10.1016/j.cep.2006.08.006.

Binoj, J. S., R. Edwin Raj, V. S. Sreenivasan, and G. Rexin Thusnavis. 2016 "Morphological, Physical, Mechanical, Chemical and Thermal Characterization of Sustainable Indian Areca Fruit Husk Fibers (Areca Catechu L.) as Potential Alternate for Hazardous Synthetic Fibers." Journal of Bionic Engineering 13 (1): 156-65. https://doi.org/10.1016/S16726529(14)60170-0.

Burakov, Alexander E., Evgeny V. Galunin, Irina V. Burakova, Anastassia E. Kucherova, Shilpi Agarwal, Alexey G. Tkachev, and Vinod K. Gupta. 2018 "Adsorption of Heavy Metals on Conventional and Nanostructured Materials for Wastewater Treatment Purposes: A Review." Ecotoxicology and Environmental Safety 148 (August 2017): 702-12. https://doi.org/10.1016/j.ecoenv.2017.11.034.

Chakravarty, Paresh, Dinesh C. Deka, Neelotpal S. Sarma, and Hari P. Sarma. 2012. "Removal of Copper (II) from Wastewater by Heartwood Powder of Areca Catechu : Kinetic and Equilibrium Studies." Desalination and Water Treatment $40 \quad(1-3)$ : https://doi.org/10.1080/19443994.2012.671167.

Chakravarty, Paresh, N. Sen Sarma, and H. P. Sarma. 2010. "Biosorption of cadmium(II) from Aqueous Solution Using Heartwood Powder of Areca Catechu." Chemical Engineering Journal 162 (3): 949-55. https://doi.org/10.1016/j.cej.2010.06.048. 
Dickhout, J. M., J. Moreno, P. M. Biesheuvel, L. Boels, R. G.H. Lammertink, and W. M. de Vos. 2017. "Produced Water Treatment by Membranes: A Review from a Colloidal Perspective." Journal of Colloid and Interface Science 487: 523-34. https://doi.org/10.1016/j.jcis.2016.10.013.

Ebrahimzadeh, Homeira, Ali Akbar Asgharinezhad, Elahe Moazzen, Mostafa M. Amini, and Omid Sadeghi. 2015. "A Magnetic Ion-Imprinted Polymer for lead(II) Determination: A Study on the Adsorption of lead(II) by Beverages." Journal of Food Composition and Analysis 41 (Ii): 74-80. https://doi.org/10.1016/j.jfca.2015.02.001.

Fadhil, Abdelrahman B., Adnan I. Ahmed, and Hamid A. Salih. 2017. "Production of Liquid Fuels and Activated Carbons from Fish Waste." Fuel 187: 435-45. https://doi.org/10.1016/j.fuel.2016.09.064.

Gupta, V. K., O. Moradi, I. Tyagi, S. Agarwal, H. Sadegh, R. ShahryariGhoshekandi, A. S.H. Makhlouf, M. Goodarzi, and A. Garshasbi. 2016. "Study on the Removal of Heavy Metal Ions from Industry Waste by Carbon Nanotubes: Effect of the Surface Modification: A Review." Critical Reviews in Environmental Science and Technology 46 (2): 93-118. https://doi.org/10.1080/10643389.2015.1061874.

Kim, Namgyu, Munsik Park, and Donghee Park. 2015. "A New Efficient Forest Biowaste as Biosorbent for Removal of Cationic Heavy Metals." Bioresource Technology 175: 629-32. https://doi.org/10.1016/j.biortech.2014.10.092.

Lalhmunsiama, Seung Mok Lee, and Diwakar Tiwari. 2013. "Manganese Oxide Immobilized Activated Carbons in the Remediation of Aqueous Wastes Contaminated with copper(II) and lead(II)." Chemical Engineering Journal 225: 128-37. https://doi.org/10.1016/j.cej.2013.03.083.

Li, Xiao ming, Wei Zheng, Dong Bo Wang, Qi Yang, Jian Bing Cao, Xiu Yue, Ting Ting Shen, and Guang Ming Zeng. 2010. "Removal of Pb (II) from Aqueous Solutions by Adsorption onto Modified Areca Waste: Kinetic and Thermodynamic Studies." Desalination 258 (1-3): 148-53. https://doi.org/10.1016/j.desal.2010.03.023.

Liu, Xiang, Guan Ru Chen, Duu Jong Lee, Tohru Kawamoto, Hisashi Tanaka, Man Li Chen, and Yu Kuo Luo. 2014. "Adsorption Removal of Cesium from Drinking Waters: A Mini Review on Use of Biosorbents and Other Adsorbents." $\quad$ Bioresource Technology 160: 142-49. https://doi.org/10.1016/j.biortech.2014.01.012.

Muslim, A, E Devrina, and H Fahmi. 2015. "Adsorption of Cu(II) From The Aqueous Solution By Chemical Activated Adsorbent of Areca Catechu Shell.” Journal Od Engineering Science and Technology 10 (12): 1654-66.

Nabanita, Haloi, and H P Sarma. 2012. "Removal of Iron from Ground Water by Using Heart Wood Charcoal of Areca Catechu." Journal of Environmental Research And Development 7 (2): 688-93.

Palanichamy, Kalyani, and Anitha Ariharaputhiran. 2013. "Areca Leaves as a Source of Carbon: Preliminary Investigation as Catalyst Support for Electrolytic Hydrogen Evolution in Acidic Medium." International Journal $\begin{array}{lllll}\text { of Hydrogen } & \text { Energy } & \text { 2263-70. }\end{array}$ https://doi.org/10.1016/j.ijhydene.2012.12.003.

Perdagangan, Dinas Perindustrian Dan. 2017. Buku Data Base Potensi Komoditi Industri Agro.

Puranik, P R, and K M Paknikar. 1997. "Biosorption of Lead and Zinc from Solutions Using Streptoverticillium Cinnamoneum Waste Biomass." J.Biotechnol. 55: 113-24.

Rani, Grandhe Usha, Ananda Kumar Konreddy, and Sumit Mishra. 2018. "Novel Hybrid Biosorbents of Agar: Swelling Behaviour, Heavy Metal Ions and Dye Removal Efficacies." International Journal of Biological Macromolecules 117 (2017): https://doi.org/10.1016/j.ijbiomac.2018.05.163.

SenthilKumar, P., S. Ramalingam, V. Sathyaselvabala, S. Dinesh Kirupha, and S. Sivanesan. 2011. "Removal of copper(II) Ions from Aqueous Solution by Adsorption Using Cashew Nut Shell.” Desalination 266 (1-3): 63-71. https://doi.org/10.1016/j.desal.2010.08.003.

Shakoor, Muhammad Bilal, Nabeel Khan Niazi, Irshad Bibi, Ghulam Murtaza, Anitha Kunhikrishnan, Balaji Seshadri, Muhammad Shahid, dkk., 2016. "Remediation of Arsenic-Contaminated Water Using Agricultural Wastes as Biosorbents." Critical Reviews in Environmental Science and Technology 46 (5): 467-99. https://doi.org/10.1080/10643389.2015.1109910.

Siddiqui, Shaziya H., and Rais Ahmad. 2017. "Pistachio Shell Carbon (PSC) an Agricultural Adsorbent for the Removal of $\mathrm{Pb}$ (II) from Aqueous Solution." Groundwater for Sustainable Development 4 (Ii): 42-48. https://doi.org/10.1016/j.gsd.2016.12.001.

Singh, Santosh, Nargis Parveen, and Himanshu Gupta. 2018. "Adsorptive Decontamination of Rhodamine-B from Water Using Banana Peel Powder: A Biosorbent." Environmental Technology and Innovation 12: 189-95. https://doi.org/10.1016/j.eti.2018.09.001.

Tong, K. S., M. Jain Kassim, and A. Azraa. 2011. “Adsorption of Copper Ion from Its Aqueous Solution by a Novel Biosorbent Uncaria Gambir: Equilibrium, Kinetics, and Thermodynamic Studies." Chemical Engineering Journal 170 (1): 145-53. https://doi.org/10.1016/j.cej.2011.03.044.

Wong, Syieluing, Norzita Ngadi, Ibrahim M. Inuwa, and Onn Hassan. 2018. "Recent Advances in Applications of Activated Carbon from Biowaste for
Wastewater Treatment: A Short Review." Journal of Cleaner Production 175: 361-75. https://doi.org/10.1016/j.jclepro.2017.12.059.

Zhang, Kui, and Tao Chen. 2018. "Dried Powder of Corn Stalk as a Potential Biosorbent for the Removal of Iodate from Aqueous Solution." Journal of Environmental Radioactivity 190-191 (February): 73-80. https://doi.org/10.1016/j.jenvrad.2018.05.008.

Zheng, Wei, Xiao ming Li, Fei Wang, Qi Yang, Pin Deng, and Guang ming Zeng. 2008. "Adsorption Removal of Cadmium and Copper from Aqueous Solution by Areca-A Food Waste." Journal of Hazardous Materials 157 (23): 490-95. https://doi.org/10.1016/j.jhazmat.2008.01.029. 